\title{
Crane Notes
}

\section{By DAYTON O. HYDE, Chiloquin, Oregon}

I live in one of the last breeding strongholds of the Greater Sandhill Crane. They are the harbingers of my spring. Their croaking voices as they wheel on effortless wing high in the heavens, summon forth the grasses from their winter sleep. They are my comparions in the fields in the long, fruitful summers, when the marshes echo with their wary, lonely notes. And they are among the last to forsake me in the fall, when their going brings on the darkened emptiness of a winter world. On a summer's day five years aso, I watched thirty-four Sandhills, dancing in a ring, great grey birds, bowing, croaking, flapping high, in sacred ritual to the Sandhill gods. When ice formed tinkling pie-plates about their long legs, one frosty autumn morning, they migrated. Spring came, but only eight returned.

I watched a lonely female feeding near her favorite nesting slough, waiting for her mate who never came, and I knew then that something concrete must be done to help the cranes. The setting up of a semicaptive breeding flock for research seemed to be an answer. So little was known and yet so much had to be known, for the benefit both of the Greater Sandhills, and of the vanishing Whooping Crane. Even then I became excited. Both species were probably of common origin; perhaps techniques which were found to help the Sandhill would help the Whooping Crane also.

One cannot hurry such projects. One year we rescued a doomed nest, and raised a female; the next year we raised a male. Since cranes do not normally breed until their second year, another year was lost to our project. At last came the eggs, two clutches of two large, mottled-brown eggs. This time we forsook our incubator for bantams.

I have long been bothered by the fact that wild Sandhills lay two eggs, hatch two young, yet never seem to have two young long after hatching. In captivity we found the answer. Sandhills begin incubation on laying their first egg, then lays the second egg. The first chick, usually about three days older, does not tolerate the younger, but turns on him with devastating results which seem as much psychological as physical. Of the two Whooping Crane chicks hatched at New Orleans in 1956 the younger chick disappeared soon after hatching "presumably to a predator." From our experience, I think that this second chick fled in complete terror of his brother. Both Sandhill clutches showed exactly the same pattern of behavior, and we were forced to raise all four chicks separately. From time to time, we tried to reconcile the nestmates, but it worked only until the older bird made a pass at the younger, and then the younger invariably fled headlong, beating itself mercilessly against any obstacle. After such attacks, it sometimes took an hour of patient soothing with choice tidbits to quiet the emotionally disturbed crane. Only when they were grown, were we able to bring them together peacefully.

From our experience with these four young came a greatly simplified hatching and feeding program, a method in which the young cranes are protected at all times by antibiotics as well as from the deadliness of mouldy food. It should be noted here that the surviving Whooping Crane chick at New Orleans died of Aspergillosis, which I have always felt, can best be prevented by food sanitation. Our simplified program could easily be applied to rescue operations in the far North, should need ever arise to rescue Whooping Crane eggs. Should it prove, for instance, that the Whooping Crane raises only one chick from its two eggs, then a method might be worked out whereby the second egg could be gathered in the three-day interim between hatchings, and the wild parents left with their one chick.

We have progressed very favorably in a method of raising cranes by food control rather than caged captivity, by which method we could conceivably raise cranes to any degree of wildness should a captive flock ever be required to step up 


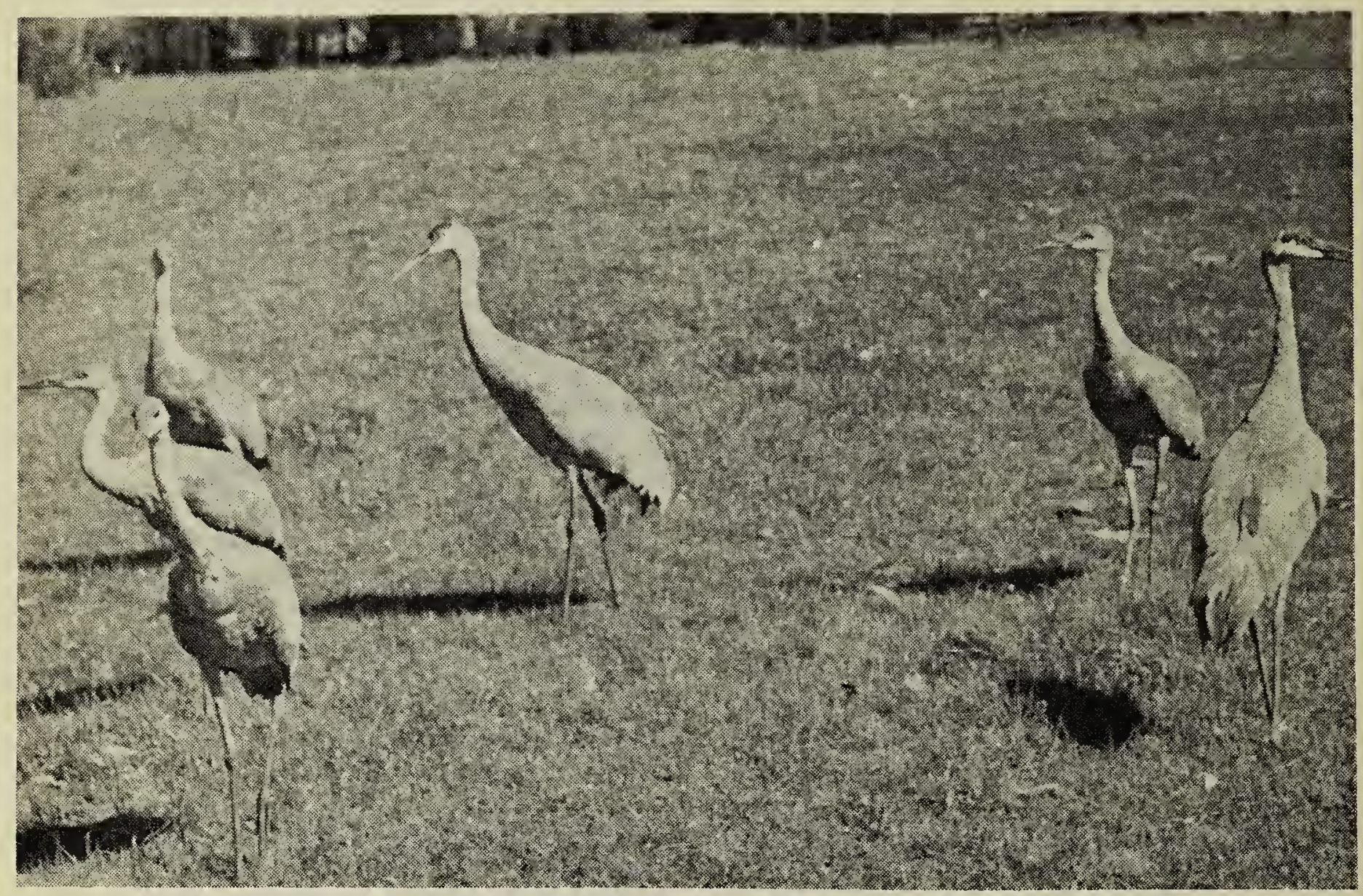

Photo by D. O. Hyde Greater Sandhill Cranes at Yamsay Ranch and four young raised from them in 1956.

production by furnishing birds to the wild flock. Our four young flew beautifully under this plan, spent as much time in the air as wild cranes, often flying to altitudes of several thousand feet.

Those who have cpposed a captive management program for the Whooping Crane have stated that young raised in captivity would be lost to the wild flock. Our experience with Sandhills would indicate otherwise. Very important is the fact that our cranes were perfectly accepted by the wild cranes with whom they flew out to consort almost daily. By September they were taking much of their food from the meadows. Eventually they spent even their nights afield, subject at these times to predators such as coyotes and eagles; yet they were alert and survived.

On the afternoon of November 14 , the young cranes were restless and circled high above this isolated valley. Once I called to them as they drifted a thousand feet above my head, and they came in as they always had, and fed for a time at my feet. But they soon went aloft again. Sadly, but a little proudly too, I watched them, knowing that the mighty instincts of migration were taking them away into the darkening heavens.

The thought of what may lie ahead in crane research excites us. We hope to determine whether or not specialized nesters, such as the Greater Sandhills, could be brought through a generation in captivity to be more tolerant of nesting areas which would not otherwise meet their requirements, and thus help the species adjust to a changing environment. What we have learned is but little compared to what needs to be learned. The time to answer the questions is now, not after the species has failed to survive. Research in birds which take two years to mature is a slow process at best. Whatever the results of the research, tie flock itself stands ready to go into production, a living guarantee that the Greater Sandhill will never become extinct.

Let us take a closer look at the Sandhill Crane and his personality in captivity. A hand-raised crane makes an affectionate and amusing companion. I have gone on long rides over the meadows and had the sandhills go along, feeding and exploring 
until I was almost out of sight; then they would fly up to rejoin me. Sometimes when busy I would attempt to escape them and would be trying to corral scme wild cattle or steal a ride on a nervous colt, when here would come my gang for a closer look, and their flapping arrival generally turned my work to complete chaos. My wife once planted a whole row of strawberry plants, only to find that the Sandhills had pulled up every plant behir.d her. Their long bills are never still, probing constantly in the earth; snapping a luckless insect off a blade of grass with pinpoint accuracy, untying one's shoelaces or picking at the buttons on one's clothes. Try to dig a can of angle-worms for fish bait and they'll beat you to every worm. Grain the calves and the Sandhills are in the grain trough for their share. A curious thing is that they never let a plane go over without putting their heads back and uttering an ear-splitting protest. To see the Sandhills dance, on $\Leftarrow$ has only to toss a small stick intc the air before them. It is seized by the nearest crane who tosses it in turn and the bouncing game is on. One can't help liking the birds. I remember a very solemn and dignified cowboy of sixty-five who came to work for us. I was certain he thought us strange indeed, to have a bunch of cranes about. My fears vanished when I came around the corner of the barn one morning. There was the old cowboy in a ring with the cranes. Hat in hand, arms flapping, a big grin on his face, he was bounding a good three feet in the air with every jump.

\section{Prairie Wildlife Habitat Meeting}

The first meeting of wildlife biologists frcm Manitoba, Saskatchewan and Alberta was held in Regina on January 16 and 17 . The purpose of the meeting was to consider habitat requirements of furbearers, upland and migratory game birds.

To provide suitable habitat, the group favoured the acquisition of land by proviricial governments. It recommended that the wetlands inventory conducted by Ducks Unlimited in Saskatchewan be: (1) continued, (2) expanded to Alberta and Manitoba and (3) entered into on a co-operative basis by the provincial game branches and the Canadian Wildlife Service. The meeting favored the extended study of habitat requirements of upland game and the exchange of population data between provinces. Discussing the pheasant programme in Alberta, the group considered an experimental hen season for comparison with the traditional cock season and suggested that staggering the opening dates for resident and non-resident hunters for pheasants on the E.I.D. might ease hunting pressure.

With furbearers, the most urgent need in the southern prairies was considered to be a study of habitat requirements of muskrat and beaver.

Waterfowl management requirements include further knowledge of habitat requirements of each species, determination of size, distribution and methods of wateifowl harvest. The problem of depredation by waterfowl, and the question of crow and magpie predation were also discussed. A study of magpie predation on game bird nests is contemplated for Alberta in 1957, because it is felt that the present programme is not "controlling" the predators or increasing production of game birds.

Possibility of initiating an experimental study of Canada Goose nesting in the Quill Lake district was discussed. The project would be carried out by Ducks Unlimited and the Canadian Wildlife Service.

\section{COVER PHOTOS WANTED}

If you have photographs that would make suitable cover pictures for the Blue Jay, we should be very glad to have them. We want black and white photographs that are sharp and clear, of any wildlife subject taken in the Prairie Provinces. In size, prints submitted should be as large as, or larger than, the actual cover picture. All photographs will be returned.

With your picture, please send details of place and date taken and any other interesting or unusual particulars. 